\title{
PENGARUH PENGGUNAAN GADGET TERHADAP PERKEMBANGAN BICARA DAN BAHASA ANAK USIA 3-5TAHUN
}

\section{The Effect Of Gadget Use With Speech And Language Development In Child Ages 3 Until 5 Years Old}

\author{
Anggun Pranessia Anggrasari', Rasi Rahagia ${ }^{2}$ \\ ${ }^{1,2}$ Prodi Profesi Ners STIKES Surabaya \\ Alamat Korespondensi : Prodi Profesi Ners \\ Jalan Medokan Semampir Surabaya \\ email: anje.pranessia@gmail.com
}

\begin{abstract}
ABSTRAK
Gadget merupakan salah satu perkembangan teknologi dan komunikasi yang tanpa disadari telah mempengaruhi setiap aspek kehidupan manusia, termasuk anak-anak. Ketika menggunakan gadget, anak menjadi kurang bersosialisasi dan berkomunikasi dengan orang lain. Hal tersebut menyebabkan anak kurang optimal mendapatkan stimulus yang tepat sehingga mengalami keterlambatan dalam aspek perkembangan bicara dan bahasa. Selama tahun 2013 sampai pertengahan tahun 2015 terjadi peningkatan masalah keterlambatan tumbuh kembang pada anak yang ditemukan melalui Deteksi Dini Tumbuh Kembang. Tujuan dari penelitian ini adalah untuk menganalisis pengaruh penggunaan gadget terhadap perkembangan bicara dan bahasa pada anak usia 3-5 tahun.

Penelitian ini termasuk jenis penelitian survey analitik menggunakan pendekatan cross sectional. Populasi penelitian berjumlah 60 responden dimana keseluruhannya akan menjadi sampel penelitian (total sampling). Instrumen penelitian menggunakan kuesioner penggunaan gadget dan KPSP. Data Yang telah dikumpulkan dianalisis menggunakan uji Chi-Square dngan kriteria signifikan $p$-value $<0,05$.

Dari hasil analisis diperoleh nilai $p$-value $0,001(p$-value $<0,05)$ yang berarti terdapat pengaruh yang signifikan antara penggunaan gadget terhadap perkembangan bicara dan bahasa pada anak usia 3-5 tahun. Hal ini mendasari bahwa pentingnya memberikan permainan edukatif kepada anak dan memberikan stimulasi selama mereka bermain.
\end{abstract}

Kata Kunci: gadget, perkembangan bicara dan bahasa, anak

Gadgets are the one of technology and communication development which has unwittingly affected every aspect of human life, including child. When using gadgets, children becomes less interaction and communicate. This can cause children to be less than optimal in getting of right stimulus so that have delay development in speech and language. There were increased number of children suffered from developmental problems during 2013 to mid-2015 based on Growth and Developmental Early Detection. The purpose of this study was to analyze effect of using gadgets to speech and language development on child.

This research used an analytic survey with cross sectional approach. The population is amount 60 respondents was taken by total sampling technique. This research used a gadgets questionnaire and KPSP. If we have been collected the data then we doing analysis method in SPSS used a ChiSquare statistic with $p$-value $<0,05$.

Statistical analysis showed p-value 0,001 (p-value $<0,05)$ which mean there was a significant effect of intensity of gadget use with speech and language developmental aspects. It was important to give an educational games to child and give stimulate during their play time.

Keyword : gadget, speech and language development, children 


\section{PENDAHULUAN}

Perkembangan bahasa merupakan aspek yang paling penting pada anak usia dini. Bahasa adalah ungkapan pikiran seseornag untuk berkomunikasi dengan orang lain. Dengan bahasa, anak akan menjadi lebih mudah untuk berkomunikasi dengan orang lain melalui lisan, isyarat, maupun tulisan. Dengan berkembangnya teknologi yang semakin canggih, media komunikasipun semakin beragam, salah satunya dengan penggunaan gadget.

Gadgetmerupakan seperangkat alat elektronik yang mempunyai berbagai macam fungsi (Novitasari dan Khotimah, 2016).Gadget menyediakan fasilitas yang variatif dari segi desain maupun aplikasi, sehingga memberikan daya tarik penggunanya untuk meluangkan waktunya bermain gadget (Prianggoro, 2013). Saat ini, gadget tidak hanya digunakan sebagai media komunikasi, akan tetapi juga sebagai sarana hiburan seperti tersedianya aplikasi games dan youtube yang membuat menarik semua orang, tak luput juga anak-anak.

Seiring perkembangan zaman, aktivitas bermain anak-anak bersama gadget menjadi sulit terpisahkan.Survei yang dilakukan oleh Common Sense Media kepada 350 orang tua di Philadelphia menunjukkan bahwa 33\% orang tua mengaku anaknya yang berusia 3-4 tahun menggunakan lebih dari satu smartphone dan sebanyak $42 \%$ mengaku anaknya menggunakan gadget untuk bermain game dan menonton video (Louis, 2015). Di Indonesia, penggunaan gadget pada anak usia 0-5 tahun menunjukkan bahwa sebanyak $23 \%$ anak suka berselancar di dunia maya tanpa pengawasan sebagai sarana bermain (Aisyah, 2015). Ketika anak bermain gadget seringkali orang tua beranggapan bahwa anak merasa senang, nyaman, dan membuat orang tua tenang untuk melakukan aktivitas lainnya. Hal ini menyebabkan orang tua jarang menemani anaknya bermain, padahal keikutsertaan orang tua dalam bermain bisa menjadi stimulus dalam tumbuh kembang mereka. Suryawan (2012) dalam penelitiannya mengemukakan bahwa anak yang terlalu fokus menggunakan gadget akan cenderung kurang berinteraksi, jarang bermain bersama temannya, dan kurang berkomunikasi sehingga dapat menyebabkan anak mengalami keterlambatan dalam aspek bicara dan bahasa. Padahal prevalensi keterlamabatan bicara dan bahasa pada anak di Indonesia cukuplah tinggi. Menurut data Profil Dinas Kesehatan Surabaya (2015) sebanyak 0,055\% balita terdapat gangguan ketika dilakukan pemeriksaan menggunakan KPSP, salah satu aspeknya yaitu pada keterlamabatan bicara dan bahasa.

$$
\text { Ibarat dua sisi mata uang, }
$$
gadgetmemiliki dampak positif dan negatif bagi tumbuh kembang anak. Dampak positif penggunaan gadget yaitu dapat menambah ilmu pengetahuan dan daya imajinatif pada seorang anak. Sedangkan, untuk dampak negatif dapat menurunkan konsentrasi belajar, anak menjadi kecanduan, masalah kesehatan akibat paparan radiasi, dan menghambat kemampuan bicara karena anak yang bermain gadget justru menikmati dunianya sendiri dan cenderung diam/ enggan berbicara. Adanya dampak dari gadget akan lebih dominan jika 
orang tua membiarkan anak bermain tanpa adanya pengawasan. Ferliana (2016) mengemukakan bahwa anak usia dini yang menggunakan gadget minimal 2 jam setiap harinya menjadi kecanduan dan mempengaruhi psikologis mereka. Padahal pada anak usia dini terdapat periode emas dimana semua kecerdasan anak akan berkembang pesat jika diberikan stimulus yang tepat. Permasalahannya intensitas tinggi dalam bermain gadget akan mempengaruhi perkembangan emosi dan sosial mereka. Intensitas waktu yang lama akan membuat anak enggan untuk melakukan aktivitas lain seperti belajar. Prasetya (2017) menunjukkan data bahwa selama 30 menit anak bermain gadget akan dapat meningkatkan resiko dalam perkembangan bahasa dan bicara anak. Penggunaan gadget pada anak merupakan sistem komunikasi satu arah dimanagadget tidak bisa memberikan umpan balik dan perkembangan bahasa anak akan menjadi terganggu

Berdasarkan uraian permasalahan di atas, peneliti tertarik untuk melakukan penelitian lebih lanjut mengenai dampak penggunaan gadget terhadap perkembangan bahasa pada anak usia 3-5 tahun. Adapun tujuan dari penelitian ini adalah untuk mengetahui seberapa besar dampak penggunaan gadget terhadap perkembangan bahasa pada anak usia 3-5 tahun..

\section{METODOLOGI}

Penelitian yang dilakukan termasuk jenis penelitian analitik survey dengan pendekatan cross sectional, dimana pengambilan data dilakukan dalam satu waktu dan satu kali pengumpulan data. Untuk populasi pada penelitian ini yaitu orang tua/ wali murid TK Al-Kamil Surabaya yang berjumlah 60 responden. Untuk teknik sampling, peneliti menggunakan total sampling dimana keseluruhan populasi menjadi responden peneliti.Istrumen penelitian menggunakan kuesioner penggunaan gadget dan Kuesioner Pra Skrining Perkembangan (KPSP) pada anak usia 36-60 bulan. Untuk penggunaan KPSP, pertanyaan yang digunakan hanya pertanyaan untuk aspek perkembangan bicara dan bahasa.

\section{HASIL DAN PEMBAHASAN}

1. Analisis Univariat

a. Penggunaan Gadget

Tabel 1.Distribusi Frekuensi Penggunaan Gadget Pada Anak Usia 3-5 tahun

\begin{tabular}{lcc}
\hline $\begin{array}{l}\text { Penggunaan } \\
\text { Gadget }\end{array}$ & Frekuensi & $\begin{array}{l}\text { Prosentase } \\
\text { (\%) }\end{array}$ \\
\hline Rendah & 0 & $0 \%$ \\
Sedang & 37 & $62 \%$ \\
Tinggi & 23 & $38 \%$ \\
\hline Jumlah & $\mathbf{6 0}$ & $\mathbf{1 0 0}$ \\
\hline (Sumber: Data Primer, November 2019)
\end{tabular}

Berdasarkan Tabel 1 dapat dilihat bahwa sebagian besar anak memiliki intensitas sedang dalam penggunaan gadget yaitu sebanyak 37 anak $(62 \%)$.

b. Perkembangan Bicara dan Bahasa Tabel 2. Distribusi Frekuensi Perkembangan Bicara dan Bahasa Pada Anak Usia 3-5 tahun

\begin{tabular}{|c|c|c|}
\hline Perkembangan & Frekuensi & Prosenta \\
\hline $\begin{array}{l}\text { Bicara dan } \\
\text { Bahasa }\end{array}$ & & se (\%) \\
\hline Normal & 39 & $65 \%$ \\
\hline Terlambat & 21 & $35 \%$ \\
\hline
\end{tabular}

(Sumber: Data Primer, November 2019) 


\section{Berdasarkan Tabel 2 dapat}

dilihat bahwa sebagian besar anak memiliki perkembangan bicara dan bahasa dalam rentang normal sebanyak

$39 \operatorname{anak}(65 \%)$.

2. Analisis Bivariat

Tabel 3. Tabulasi Silang Penggunaan Gadget Tehadap Perkembangan Bicara dan Bahasa Pada Anak Usia 3-5 tahun

\begin{tabular}{|c|c|c|c|c|c|}
\hline & & $\begin{array}{l}\text { Perkemban } \\
\text { dan Bahasa }\end{array}$ & an Bicara & Total & \\
\hline & & Normal & Terlambat & & \\
\hline \multirow{7}{*}{$\begin{array}{l}\text { Penggunaan } \\
\text { Gadget }\end{array}$} & \multirow[t]{2}{*}{ Rendah } & 0 & 0 & 0 & \multirow{6}{*}{$\begin{array}{l}p \text {-value } \\
0,001\end{array}$} \\
\hline & & 0 & 0 & 0 & \\
\hline & \multirow[t]{2}{*}{ Sedang } & 26 & 11 & 37 & \\
\hline & & 70,3 & 29,7 & 100 & \\
\hline & \multirow[t]{2}{*}{ Tinggi } & 13 & 10 & 23 & \\
\hline & & 56,5 & 43,5 & 100 & \\
\hline & Total & 39 & 21 & 60 & \\
\hline
\end{tabular}

(Sumber: Data Primer, November 2019)

Berdasarkan Tabel 3 dapat dilihat bahwa sebagian besar anak berada pada penggunaan gadget dengan intensitas sedang dan perkembangan normal sebanyak 26 anak (70,3\%). Selain itu, setelah dilakukan analisis menggunakan uji Chi-Squaredidapatkan pvalue 0,001 , yang menunjukkan bahwa nilai $\mathrm{p}<\alpha$. Hasil ini menunjukkan bahwa $\mathrm{Ha}$ diterima sehingga hipotesis penelitian menyatakan terdapat pengaruh penggunaan gadget terhadap perkembangan bicara dan bahasa pada anak usia 3-5 tahun.

Berdasarkan hasil penelitian di TK AL-Kamil Surabaya menunjukkan bahwa sebagian besar anak menunjukkan intensitas yang sedang dalam penggunaan gadget yaitu sebanyak 37 anak (62\%). Hal ini menunjukkan bahwa responden setiap harinya bermain gadget lebih dari 30 menit. Sejalan dengan penelitian yang dilakukan oleh Trinika dkk (2015) mengemukakan bahwa menggunakan gadget selama 45 menit sehari dengan 3 kali bermain termasuk dalam kategori sedang.
Penggunaan gadget intensitas yang sedang sampai tinggi dapat memberikan dampak negative pada anak. Handrianto (2013) menyebutkan bahwa gadget memberikan dampak negatif pada anak, seperti penurunan konsentrasi dalam belajar, anak tidak terlalu fokus dalam belajar, dan anak cenderung kurang berinteraksi dikarenakan anak lebih menyukai menonton youtube atau bermain games daripada beraktivitas lainnya. Bermain gadget dapat membuat kemampuan psikomotorik anak tidak berkembang sempurna dikarenakan anak usia pra sekolah harus mengeksplorasi dirinya dalam aktivitas permainan yang beragam dibandingkan hanya dengan bermain gadget. Anak hanya disibukkan dengan gadget yang mempunyai umpan balik searah, sehingga aspek motorik bicara dan bahasa yang seharusnya dapat distimulus dengan tepat menjadi terganggu.

Untuk identifikasi aspek perkembangan bicara dan bahasa pada anak menunjukkan bahwa sebagian besar anak 
menunjukkan perkembangan yang normal yaiu sebanyak 39 anak (65\%). Berdasarkan hasil observasi dan pengumpulan data memang responden memiliki perkembangan bahasa yang baik, namun ada beberapa anak yang perkembangan bicara dan bahasanya belum optimal sebanyak 21 anak (35\%) yang mengalami keterlambatan dalam aspek perkembangan bicara dan bahasa. Prevalensi angka yang cukup tinggi dibandingkan penelitian yang dilakukan oleh Mardiana (2016) bahwa sebanyak $8,2 \%$ anak usia toddler mengalami suspect pada perkembangan bicara dan bahasa.

Perkembangan bicara dan bahasa pada anak menjadi aspek utama dari seluruh perkembangan yang ada dikarenakan akan mengganggu aspek perkembangan yang lainnya. Perkembangan dalam berbahasa dapat dipengaruhi oleh kemampuan kognitif, psikologis, sensori motorik, emosi, dan lingkungan sekitar anak (Kemenkes RI, 2013). Secara umum perkembangan bicara dan bahasa pada anak dapat mengembangkan kemampuan kognitif dan dasar anak sehingga anak dapat mengungkapkan ekspresi, perasaan, imajinasi, dan pikiran mereka. Perkembangan bicara dan bahasa yang mengalami keterlambatan akan mempengaruhi kehidupan anak ke depannya (Tiel, 2011 dalam Wijaya, 2015). Hal ini bisa disebabkan oleh beberapa faktor seperti kurangnya motivasi dan stimulus yang diberikan dan perolehan bahasa yang didapat masih minimal. Hal ini sejalan dengan teori yang dikemukakan oleh Hurlock (1991) dalam Bawono (2017) yang menyampaikan bahwa penyebab anak mengalami keterlambatan dalam bicara akibat kurang motivasi, kesempatan praktik bercakap-cakap yang minim, adanya bahasa asing, dan ketidakmampuan mendorong anak untuk berbicara. Dalam hal ini responden hanya memahami bahasa dan isyarat dari gadget tanpa adanya komunikasi timbal balik yang dapat melatih aspek bicara dan bahasanya.

Berdasarkan hasil uji Chi-Square menunjukkan $p$-value $0,001<0,05$, sehingga dapat disimpulkan adanya dampak penggunaan gadget terhadap perkembangan bicara dan bahasa pada anak usia 3-5 tahun. Hal ini sejalan dengan penelitian Trinika (2015) yang menunjukkan hasil signifikan antara penggunaan gadget dengan perkembangan psikososial anak usia pra sekolah. Penggunaan gadget dapat membuat peran keluarga dan teman menjadi tergantikan dengan kehadiran gadget, sehingga anak lebih menyukai bermain sendiri dan tidak melakukan interaksi dengan anak lain. Sedangkan psikososial yang terganggu dapat menyebabkan anak menjadi gagap dan terlambat dalam bicara (Soetjiningsih, 2014).

$$
\text { Jurka dan Pija Samec (2012) }
$$
mengemukakan bahwa penggunaan gadget pada usia balita dapat mempengaruhi aspek perkembangan bicara dan bahasanya. Gadget yang digunakan secara berlebihan, tidak terkontrol, dan tanpa pengawasan dapat menyebabkan akan kurang bersosialisasi atau berkomunikasi dengan orang sekitarnya. Hal ini sesuai dengan teori Soetjiningsih ( yang menyatakan bahwa anak yang kurang mendapatkan stimulus pada aspek 
perkembangannya dapat mengganggu kemampuan bicara dan bahasanya. Selain itu, aplikasi yang terdapat pada gadget sangat bervariasi tidak hanya aplikasi untuk belajar yang dapat meningkatkan perkembangan anak, akan tetapi aplikasi hiburan yang paling diminati oleh mereka. Peran dan pendampingan orang tua sangatlah penting ketika anak bermain gadget. Orang tua dapat memberikan dan menunjukkan kepada anak aplikasi yang edukatif seperti mengenal huruf, hewan, dan lainnya. Dengan pengawasan yang tepat dan stimulus yang sesuai akan memberikan dampak positif pada anak diantaranya meningkatkan pengetahuan, mengembangkan imajinasi dan kreativitas anak, dan belajar mengeksplorasi apa yang ada sehingga motivasi dan minat belajar anak akan cukup tinggi.

\section{KESIMPULAN}

Berdasarkan tujuan penelitian yang telah diuraikan sebelumnya, maka dapat diambil kesimpulan bahwa anak berada pada intensitas sedang dalam penggunaan gadget yaitu lebih dari 30 menit sehari dan sebagian kecil responden mengalami keterlambatan dalam aspek bicara dan bahasa. Hasil uji analisis Chi-Square juga menunjukkan bahwa terdapat pengaruh penggunaan gadget terhadap perkambangan bicara dan bahasa pada anak usia 3-5 tahun.

\section{SARAN}

Bagi masyarakat diharapkan untuk lebih aktif bermain dan berinteraksi dengan anak, serta memberikan permainan edukatif untuk meningkatkan tumbuh kembang anak.
Sedangkan untuk peneliti selanjutnya dapat meneliti kembali menggunakan sampel yang lebih banyak atau menggunakan variabel lain yang dapat berpengaruh pada aspek perkembangan bicara dan bahasa anak.

\section{DAFTAR PUSTAKA}

Bawono, Y. 2017. Kemampuan berbahasa Pada Anak Pra Sekolah: Sebuah Kajian Pustaka. Prosiding Temu Ilmiah $X$ Ikatan Psikologi Perkembangan Indonesia.

Soetjiningsih. 2014. Tumbuh Kembang Anak Edisi 2. Jakarta: EGC.

Novitasari, Wahyu., dan Khotimah, Nurul. 2016. Dampak Penggunaan Gadget Terhadap Interaksi Sosial Anak Usia 5-6 Tahun [Online] $<$ ejournal.unesa.ac.id/article/21231/19 /article.pdf $>$ [Diakses 27 Desember 2019 Pk. 22.01 WIB]

Prianggoro, Hasto. 2013. Anak dan Gadget: Yang Penting Aturan Main. Tabloid Nakita. 1 Oktober. Tersedia di: $<$ http://www/tabloidnakita.com/read/1/anak-dan-gadgetyang-penting-aturan-main $>$ [Diakses 30 Desember 2019 Pk. 12.30 WIB]

Louis, C. Saint. 2015. Many Children Under 5 Are Left to Their Mobile Devices, Survey Finds. Tersedia di: $<$ http://www.nytimes.com/2015/11/02/ health/many-children-under-5-are-leftto-their-mobile-devices-surveyfinds.html> [Diakses 30 Desember 2019 Pk. 12.35 WIB]

Aisyah, Siti. (2015). Kasus pengguna Gadget pada anak usia dini.Tersedia di: $<$ http://aisyahsiti02.blogspot.com/201 5/02/kasus-pengguna-gadget-padaanak-usia.html> [Diakses 30 Desember 2019 Pk. 12.40 WIB]

Dinas Kesehatan Kota Surabaya. 2015. Kesehatan Dasar. Surabaya : Dinkes.

Surayawan, A. 2012. Penyebab Anak Alami Keterlambatan Bicara. Surabaya: Jawa Pos.

Ferliana, Jovita Maria. (2016). Anak dan Gadget Yang Penting Aturan Main. Tersedia di: $<$ http://nakita.grid.id/balita/anakdangadget-yang-penting-aturan- 
main?page $=21>[$ Diakses 30 Desember 2019 Pk. 12.40 WIB]

Prasetya, Fauzan Budi. (2017). Terbukti, Balita yang sering pakai Gadged berisiko Keterlambatan Bicara. Tersedia di: <http:// hellosehat.com/parenting/perkembang an-balita/pengaruh-gadget-bicaraanak/> [Diakses 30 Desember 2019 Pk. 12.45 WIB]

Nursalam. 2013. Metodologi Penelitian Kesehatan.Jakarta: Rineka Cipta.

Padmonodewo. 2013. Pendidikan Anak Pra Sekolah. Jakarta: Rineka Cipta.

Handrianto, P. 2013. Dampak Smartphone. Tersedia di: <http://sainsjournalfst11.web.unair.ac.id/artikel_detail75305-KESEHATAN-

Dampak\%20Smart\%20phone.html> [Diakses 30 Desember 2019 Pk. 12.50 WIB]

Trinika, Yulia. 2015. Pengaruh Penggunaan Gadget Terhadap Perkembangan Psikososial Anak Usia Prasekolah (3-6 tahun) di TK Swasta Kristen Immanuel Tahun Ajaran 2014-2015. Jurnal ProNers 3.1.

Kementerian Kesehatan Republik Indonesia. 2013. Pedoman Pelaksanaan Stimulasi, Deteksi, dan Intervensi Dini Tumbuh Kembang Anak di Tingkat Pelayanan Kesehatan Dasar. Jakarta: Kemenkes RI.

Wijaya, Susiana. 2015. Efektivitas Pelatihan Identifikasi Dini Keterlambatan Bicara Pada Anak Usia Pra Sekolah Untuk Meningkatkan Kompetensi Pedagogik Guru PAUD. Prosiding Seminar Nasional 978-602-71716-2-6.

Jurka and Pija Samec. 2012. Advantages and Disadvantages of InformationCommunication Technology Usage for Four-Year-Old Children, and The Concequences of Its Usage for The Chilldren Develompent. International Journal of Humanities and Social Sciences Vol 2 No 3. 